\title{
A connection between geomagnetic intensity and climatic anomalies recorded in Chinese loess
}

\author{
Jiasheng Chen ${ }^{a, b} *$ Xiuming Liu ${ }^{a, c, d}$
}

a'Key Laboratory of Western China's Environmental Systems, Research School of Arid Environment \& Climate Change, Lanzhou University, Lanzhou 730000, China

${ }^{b}$ Department of Physics, University of Alberta, Edmonton, Alberta T6G 2E1, Canada

${ }^{c}$ Key Laboratory of Humid Sub-tropical Eco-geographical Process of Ministry of Education, School of Geographical Sciences, Fujian Normal University, Fuzhou 350007, China

dDepartment of Environment and Geography, Macquarie University, Sydney NSW 2109, Australia

* Corresponding author: chenjsh04@gmail.com

\section{Abstract}

Quaternary climate change recorded by Chinese loess closely parallels fluctuations in the benthic $\delta^{18} \mathrm{O}$ record. However, there are also some unique climate anomalies in and around the Asian inland Chinese Loess Plateau (CLP), where the climate was unusually humid during MIS 3 and 13, and extremely cold during MIS 22 and 38. Most explanations involve modifications to atmospheric circulation, but there is no single answer for such anomalies. Here, we compare relative geomagnetic paleointensity with benthic $\delta^{18} \mathrm{O}$, and find that all anomalies occur when paleointensity negatively correlates with $\delta^{18} \mathrm{O}$. The reason for this is not yet clear. Milankovitch theory fundamentally explains Quaternary climatic cycles by external forcing. Our results suggest that changes in the Earth's deep interior, especially geomagnetic field intensity, may play a significant role in some non-linear climate changes in mid-latitude long-term Quaternary climate change. We are currently pursuing the idea that fluctuations in global climatic background $\left(\delta^{18} \mathrm{O}\right.$ record) and cosmic ray influx, which is controlled by the strength of the geomagnetic field, may from time to time act in concert to create regional anomalies such as those seen on the CLP. 
Keywords: Chinese loess, Climate anomalies, Geomagnetic intensity, Non-linear climate changes

\section{Introduction}

Quaternary climate change has been reconstructed by isotopic composition of deep-sea

foraminiferal $\delta^{18} \mathrm{O}$ records. $\delta^{18} \mathrm{O}$ is sensitive to the deep-sea temperature and ice volume changes. High $\delta^{18} \mathrm{O}$ usually corresponds to high ice volume and low temperature in the Northern Hemisphere. High ice volume enhances the Siberian High centered at the Asian inland in winter and increases thermal differences between the Asian landmass and the Pacific Ocean. It results in strong winter monsoon blowing from Asian inland to the southeast ocean. Chinese loess is transported by the winter monsoon from the inland Gobi desert to the CLP (Liu and Ding, 1998). Coarse grain size of loess reflects strong winter monsoon, which indicates cold and dry winter conditions (Liu and Ding, 1998). Low $\delta^{18} \mathrm{O}$ corresponds to low ice volume and high temperature. The low ice volume suggests that abundant meltwater pours into the ocean, the sea level rises and the Asian inland is closer to the ocean. It enhances the East Asian Summer Monsoon and brings more precipitation from the southeast ocean to the CLP. Magnetic susceptibility $(\chi)$ values of Chinese loess are mainly determined by the amount of ferrimagnetic material, which is mostly produced by soil development due to the summer monsoon (Zhou et al., 1990). High $\chi$ reflects strong summer monsoon and humid summer climate. Chinese loess-soil sequences correlate well with the $\delta^{18}$ O records (Heller and Liu, 1984; Kukla, 1987; Liu and Ding, 1998).

However, there are also some unique regional climatic anomalies on the CLP and adjacent Tibetan Plateau (TP). During Marine Isotope Stage (MIS) 3, the ${ }^{10} \mathrm{Be}$ curve of the Weinan loess, the pedogenic magnetic susceptibility flux curve of the Luochuan loess and the sea surface temperature changes in a South China Sea core all show an unusual increase in precipitation during 35-25 ka (An, 2000). Furthermore, numerous lakes in western China and TP reached high levels, whereas today they are dry (Shi et al., 2001). The Guliya ice core record on the TP shows that the temperature of late MIS 3 is $4 \mathrm{C}^{\circ}$ warmer than present (Shi et al., 2001). For MIS 13, $\chi$ of Chinese loess implied an extremely humid climate (Ding et al., 1999; Guo et al., 2009; Yin and Guo, 2008). Meanwhile, the TP experienced unusually intense interglacial conditions (Chen et al., 1999), and the productivity in the 
Arabian Sea was very high (Ziegler et al., 2010). MIS 22 to 24 (L9 in loess stratigraphy) and MIS 38 (L15) of Chinese loess is described as "sandy loess", which suggests extremely cold and dry climate, and are widely used as stratigraphic markers for their distinctive morphological characteristics observed in the field (Guo et al., 1998; Sun and Liu, 2000). The MIS 3 anomaly has been associated with the increase of thermodynamic contrast between the TP and the Indian Ocean (Shi et al., 2001). The MIS 13 anomaly has been related to the asymmetry of hemispheric ice sheets (Guo et al., 2009; Yin and Guo, 2008), or to the onset of an intensive meridional overturning circulation in the Atlantic Ocean (Ziegler et al., 2010). For the cold and dry L9 and L15 intervals, some studies (Li and Fang, 1999; Sun, 2000; Xiao and An, 1999) associated it with uplift of the TP, whereas Guo et al., (1998) linked these climatic extremes to the Atlantic-Pacific $\delta^{13} \mathrm{C}$ gradients induced by the Atlantic thermocline circulation. There is no single answer for all anomalies.

Several authors have proposed links between climate and geomagnetic field intensity (see Courtillot et al., (2007) for a summary). Kirkby, (2007) discussed the interaction between the geomagnetic field, cosmic rays and climate. Knudsen and Riisager, (2009) suggested there was a link between Earth's magnetic field and low-latitude precipitation. Kitaba et al. (2013) found that geomagnetic field minima during polarity reversals decrease mid-latitude temperatures. Valet et al. (2005) and Channell et al. (2009) have reconstructed Quaternary relative paleointensity patterns (Sint-2000 and PISO-1500, respectively). Lisiecki and Raymo (Lisiecki and Raymo, 2005) established a $\delta^{18} \mathrm{O}$ stack from 57 globally distributed benthic $\delta^{18} \mathrm{O}$ records. Here, we tentatively use these geomagnetic intensity and global climate records to interpret the CLP and TP anomalies in a uniform manner.

\section{Method and Results}

We compare various time series (e.g. PISO-1500 and LR04) by means of cross correlation, using a $100 \mathrm{ky}$ sliding window, advanced in $1 \mathrm{ky}$ increments. The $100 \mathrm{ky}$ window was chosen in order to envelop the common Milankovitch cycles. Climate change may take time to respond to the driving force, and age uncertainties exist in both records. These factors adversely affect the correlation between the records. We therefore computed cross-correlation function $\left(\mathrm{X}_{\mathrm{CF}}\right)$ values for lags of $0, \pm 1, \pm 2 \mathrm{ky}$. Only the values exceeding the $95 \%$ confidence limit were retained for further analysis. 
We use the magnetic susceptibility $(\chi)$ and mean grain size (Md) of the Lingtai section (Sun et al., 2010) to represent the variations of summer and winter monsoons on the central CLP. Fig. 1(a) shows the $\chi$ and Md records of the Lingtai section (Sun et al., 2010). Maximum $\chi$ values occur during soil unit S5, corresponding to MIS 13 (Fig. 1(a)), and the amplitude of $\chi$ variations also increase considerably since then. The highest Md occurs during loess unit L15 (MIS 38), and the second highest value falls in L9 (MIS 22), The grain size variations of several loess sections (e.g., (Ding et al., 2002; Lu et al., 2003; Sun et al., 2006)) all suggested that the loess units L9 and L15 represent the coarsest loess of the last 2.5 Ma. For L1S (MIS 3), $\chi$ and Md do not show anomalous values. An (2000) and Shi et al. (2001) suggested unusually humid conditions during 40-30 ka on south part of the CLP and adjacent TP.

The LR04 benthic $\delta^{18} \mathrm{O}$ stack (Fig.1 (b) and (c)) values show no unusual variations around MIS 3, 13, 22 and 38. Moreover, the loess records in Tajikistan, west of the TP, do not show any anomalies around MIS 3, 13, 22, 38 (Ding et al., 2002). The atypical climates on the CLP and TP around MIS 3, 13, 22 and 38 are regional effects in middle and low latitudes, and are not seen globally.

Fig.1 (b) and (c) shows the variations of PISO-1500 (Channell et al., 2009) and Sint-2000 (Valet et al., 2005). Both paleointensity records appear to correlate negatively with $\delta^{18} \mathrm{O}$ around MIS 3, 13, 22, 38 and 46. This can be seen more clearly in the expanded panels in Fig. 2. PISO-1500 and Sint-2000 both show similar patterns to $\delta^{18}$ O during 40-90, 500-600, 840-980, 1140-1280, and 1400-1500 ka.

Fig. 3 illustrates the cross correlation between paleointensity and $\delta^{18} \mathrm{O}$ calculated as described above. Fig. 3(a) shows that paleointensity correlates inversely with $\delta^{18} \mathrm{O}$ centering at 52, 465-549, 844-901, 1198-1290, 1362-1440 ka. The best $X_{C F}$ values are $-0.45,-0.76,-0.62,-0.73$ and -0.43 , respectively (Fig. 3(b)). These high-correlation intervals are almost coincident with the results in Fig. 1 and 2. The blank areas in Fig. 3 (a) and (b) mean that the $\mathrm{X}_{\mathrm{CF}}$ between paleointensity and climate during these intervals do not reach 95\% confidence. The high correlations centering at 52, 465-549, 844-901 and 1198-1290 ka are consistent with intervals of climatic anomalies on CLP and TP, suggesting these climatic anomalies may relate to the interactions between the geomagnetic field and ice volume changes. 


\section{Discussion}

Intensity of natural remanent magnetization (NRM) depends on the intensity of the geomagnetic field that oriented the magnetic grains and also on the concentration of magnetic particles. $\chi$, anhysteretic remanent magnetization (ARM) and isothermal remanent magnetization (IRM) can represent the variation in concentration and size of magnetic particles. Hence, NRM/ $\chi, \mathrm{NRM} / \mathrm{ARM}$ and NRM/IRM could be indicators of relative paleointensity change (Tauxe, 1993; Valet, 2003). Both PISO-1500 and Sint-2000 are based on this method. However NRM, $\chi$, ARM and IRM are easily altered by climate signals. However, Valet et al. (2005) and Channell et al. (2009) have validated the geomagnetic origin of Sint-2000 and PISO-1500 records. Within the intervals around MIS 3, 13, 22, and 38, there are several established geomagnetic excursions (see Fig. 1). Unlike geomagnetic reversals, excursions are short-lived dramatic pole orientation shifts, with sharp decreases in field intensity (Gubbins, 1999). The excursions in Fig. 1 have been confirmed by volcanic records (Laj and Channell, 2007). Relative paleointensity stacks show minimum values when geomagnetic excursions occur, also supporting their geomagnetic origin.

Climate change is regulated by the three orbital parameters: precession, obliquity and eccentricity (Hays et al., 1976). The geomagnetic field arises from the dynamo acting in the liquid-iron outer core (Gubbins, 2008). Fuller, (2006) suggests that geomagnetic reversals preferentially occur when the average amplitude of the obliquity signal is low. Tilgner (2006) found that precession-driven dynamos can exist at magnetic Reynolds number characteristic of the Earth's core. Orbital cycles could change the geodynamo behavior. The geomagnetic intensity is affected by several geodynamo behaviors, such as the changes axial dipole strength, dipole tilt and in low order components of the non-dipole field. It is likely that the orbital cycles and the induced geodynamo behaviors changes may be reflected by geomagnetic intensity changes, in some intervals, for example around MIS $3,13,22$, and 38 , and therefore similarity between paleointensity and climate change could be attributed to orbital changes.

Kirkby, (2007) summarized the links between Galactic Cosmic Rays (GCR) and climate. Increased GCR flux appears to be associated with increased cloud cover. As clouds are 
known to exert a strong net radiative cooling effect on Earth, this would provide the necessary amplification mechanism and also the sign of the effect: increased GCRs should be associated with cooler temperatures. Hence, higher paleointensity will correlate with higher shielding, resulting in reduced cosmic radiation and cloud cover, thus higher temperature (Bard and Delaygue, 2008).

The modulation of cosmic rays by the geomagnetic field is greatest at the equator (Steig et al., 1996). In the tropics and subtropics (low and mid latitude), increased GCR flux is associated with weakening of the monsoon (Kirkby, 2007). Kitaba et al., (2013) found that geomagnetic field minima during polarity reversals were able to cool mid-latitudinal climate. Usoskin et al., (2008) proposed the possible effect of GCR should be at mid-latitudes. Earth's dipole field is lower at low latitude, and thus changes in the geomagnetic shielding of GCR particles is maximum at low latitudes and disappears at higher latitudes (Knudsen and Riisager, 2009). Hence, the effect of geomagnetic intensity on climate is fairly strong in middle latitudes.

CLP is characterized by a strong monsoon. This area has the strongest interactions between land (the vast Eurasian continent and the high Tibetan Plateau) and the sea (the Pacific Ocean and the Indian Ocean). High paleointensity correlates with high shielding, reduced cosmic radiation and cloud cover, Earth's surface receives more solar heating energy and become warmer (Fig. 4). Land temperature rises more quickly than the sea under the same solar heating increment because land has lower heat capacity. Such temperature imbalance enhances the summer monsoon blowing from the sea to land. Hence, the high paleointensity will enhance the summer monsoon on the CLP. Low paleointensity corresponds to low shielding, high cosmic radiation, high cloud cover, and low temperature. The land temperature decreases faster than the sea, enhancing the winter monsoon on the CLP (Fig. 4).

In addition to the land-sea contrast, the climate at the East Asia is affected by large-scale mountain ranges and the TP (Yeh et al., 1957). The TP is a source of heated air in summer, which lowers the atmospheric pressure, and the surrounding surface air converges toward the plateau. It reinforces the East Asian summer monsoon. During the winter, the surrounding surface air diverges from the plateau, strengthening the winter monsoon (Yeh et al., 1957). The high paleointensity and the induced reduced cloud cover helps the TP 
receive more solar heating energy. In summer, it enhances the East Asian summer monsoon over the CLP and TP. The feedback process of low paleointensity and its role on the thermal effect of the TP are supposed to strengthen the winter monsoon over the CLP and TP.

Fig. 1 and 2 show the negative correlations between $\delta^{18} \mathrm{O}$ and geomagnetic field during MIS 3, 13, 22, 38 and 46. During MIS 3 and 13, the low LR04 $\delta^{18} \mathrm{O}$ values suggest high temperature and low ice volume. Such a global climatic background usually corresponds to warm and humid climate on the CLP (Liu and Ding, 1998). The $\delta^{18} \mathrm{O}$ values are not anomalous in MIS 3 and 13, as the sea level rise and land-sea thermal contrast related to the ice volume changes at both intervals are not higher than other interglacial stages. They are only able to cause a normal strength summer monsoon on the CLP and TP, with warm and humid climate. The climatic effects of the high relative paleointensity further enhance the summer monsoon at middle and low latitudes (Fig. 4). The combined actions of global climatic background and the climatic effect of geomagnetic intensity on the CLP and TP produce extremely humid climate.

The MIS 3 climatic anomaly is not evident in the susceptibility record on the Lingtai section (Fig. 1(a)), but it is reflected by ${ }^{10} \mathrm{Be}$ curve of the Weinan loess and the pedogenic magnetic susceptibility flux curve of the Luochuan loess on the CLP and occurs at the low-latitudinal South China Sea (An, 2000). The $\delta^{18} \mathrm{O}$ record suggests that climate during MIS 3 is cooler than MIS 13 and other interglacial periods. The combined actions of global climatic background and the climatic effect of geomagnetic intensity during MIS 3 should be weaker than in MIS 13. The MIS 3 anomaly may not occur at the Lingtai section or the susceptibility at the section may be not sensitive to the anomaly.

The high $\delta^{18} \mathrm{O}$ in MIS 22 and 38 suggest high ice volume and low temperature, which strengthen the Siberian High. The strong Siberian High enhances the winter monsoon. The resonance of the cold effects of ice volume and low geomagnetic intensity cause cold anomalies during MIS 22 and 38 (Fig. 4). Hence, we speculate that the climatic anomalies on CLP and TP around MIS 3, 13, 22, and 38 are likely to be caused by the resonance of ice volume and temperature represented by $\delta^{18} \mathrm{O}$ and geomagnetic field on temperature and rainfall variations at mid-latitude. 
The $\delta^{18} \mathrm{O}$ and geomagnetic intensity show low values in MIS 14 and 36. The climate during both intervals was not extremely cold. MIS 14 and 36 are close to MIS 13 and 38, respectively. Only one anomalous event occurs in each segment of high correlation of the $\delta^{18} \mathrm{O}$ and geomagnetic intensity, which needs further investigation. Records from other areas, such as the Tajikistan loess records, do not show any anomalies around MIS 3, 13, 22, and 38 (Ding et al., 2002). The Tajikistan loess is at higher latitude $\left(38.4^{\circ} \mathrm{N}\right)$, and the climatic effect of the paleointensity changes is weak at high latitude. It is far from the sea, and the climate is dry in summer and wet in winter. The latitude, topography, and climatic conditions there are different from the East Asian monsoon area, and the climatic effect of the paleointensity needs more investigation.

Around $1400 \mathrm{ka}$, the negative correlations of LR04 with Sint-2000 and PISO-1500 (Fig. 1 and 2) appear to have no unusual $\chi$ and Md changes (Fig. 1). On the western CLP, Li et al. (1997) found that the Huanghe River had seven terraces formed at about 1660, 1400, 1100, 600,120 , and $55 \mathrm{ka}$, which are shaped by climatic shifts. The terraces and the climatic shifts around 1400,1100, 600, and $55 \mathrm{ka}$ are consistent with the age of negative correlation between paleointensity and LR04 $\delta^{18} \mathrm{O}$. On the eastern CLP, Ning et al., (1994) identified a major enhancement in the ${ }^{10} \mathrm{Be}$ concentration at $1400 \mathrm{ka}$. Both facts indicate that there is probably a climate anomaly at $1400 \mathrm{ka}$.

\section{Conclusions}

The climates on CLP around MIS 3, 13 and MIS 22, 38 are extremely humid $(3,13)$ and cold $(22,38)$. These anomalies do not exist in ice volume and temperature change reflected by stacked benthic $\delta^{18} \mathrm{O}$ records, but they all happen when the benthic $\delta^{18} \mathrm{O}$ inversely correlates with the relative geomagnetic intensity records Sint-2000 and PISO-1500. We propose that climatic anomalies on CLP and TP are caused by the interactions between global climatic background (ice volume or temperature represented by benthic $\delta^{18} \mathrm{O}$ ) and geomagnetic intensity changes. We also tentatively explain the mechanism. Low/high benthic $\delta^{18} \mathrm{O}$ usually corresponds to strong summer/winter monsoon on the CLP and TP. High/low geomagnetic intensity is able to enhance the summer/winter monsoon on the CLP and TP. Their resonant effect will enhance the strength of the East Asian monsoon and result in climatic anomalies on the CLP and TP. 
Milankovitch theory fundamentally explains the Quaternary climatic cycles by external forcing, such as solar insolation and Earth's orbital change. Our result suggests that changes from Earth's interior, expressed by the geomagnetic field intensity variations, may play a substantial role during some non-linear climate changes.

\section{Acknowledgements}

We thank the National Science Foundation of China (NSFC grants 4077210940830105, 41202129 and 40721061) and the University of Alberta for support of this study. The China Scholarship Council supported the joint China/Canada Ph.D. program for JC. Ted Evans and Vadim A. Kravchinsky are gratefully acknowledged for their thoughtful comments on this manuscript.

\section{References}

An, Z., 2000. The history and variability of the East Asian paleomonsoon climate. Quaternary Science Reviews 19, 171-187.

Bard, E., Delaygue, G., 2008. Comment on - "Are there connections between the Earth's magnetic field and climate?". Earth and Planetary Science Letters 265, 302-307.

Channell, J.E.T., Xuan, C., Hodell, D.A., 2009. Stacking paleointensity and oxygen isotope data for the last 1.5 Myr (PISO-1500). Earth and Planetary Science Letters 283, 14-23.

Chen, F., Bloemendal, J., Zhang, P., Liu, G., 1999. An 800 ky proxy record of climate from lake sediments of the Zoige Basin, eastern Tibetan Plateau. Palaeogeography, Palaeoclimatology, Palaeoecology 151, 307-320.

Clark, P.U., Archer, D., Pollard, D., Blum, J.D., Rial, J.A., Brovkin, V., Mix, A.C., Pisias, N.G., Roy, M., 2006. The middle Pleistocene transition: characteristics, mechanisms, and implications for long-term changes in atmospheric $\mathrm{pCO}_{2}$. Quaternary Science Reviews 25, 3150-3184.

Courtillot, V., Gallet, Y., Le Mouel, J.-L., Fluteau, F., Genevey, A., 2007. Are there connections between the Earth's magnetic field and climate? Earth and Planetary Science Letters 253, 328-339.

Ding, Z., Derbyshire, E., Yang, S., Yu, Z., Xiong, S., Liu, T., 2002. Stacked 2.6-Ma grain size record from the Chinese loess based on five sections and correlation with the deep-sea 
$\delta 180$ record. Paleoceanography 17, 5-1-5-21.

Ding, Z., Xiong, S., Sun, J., Yang, S., Gu, Z., Liu, T., 1999. Pedostratigraphy and paleomagnetism of a 7.0 Ma eolian loess-red clay sequence at Lingtai, Loess Plateau, north-central China and the implications for paleomonsoon evolution. Palaeogeography, Palaeoclimatology, Palaeoecology 152, 49-66.

Fuller, M., 2006. Geomagnetic field intensity, excursions, reversals and the 41,000-yr obliquity signal. Earth and Planetary Science Letters 245, 605-615.

Gubbins, D., 1999. The distinction between geomagnetic excursions and reversals. Geophysical Journal International 137, F1-F3.

Gubbins, D., 2008. Earth science - Geomagnetic reversals. Nature 452, 165-167.

Guo, Z., Berger, A., Yin, Q., Qin, L., 2009. Strong asymmetry of hemispheric climates during MIS-13 inferred from correlating China loess and Antarctica ice records. Climate of the Past 5, 21-31.

Guo, Z.T., Liu, T.S., Fedoroff, N., Wei, L.Y., Ding, Z.L., Wu, N.Q., Lu, H.Y., Jiang, W.Y., An, Z.S., 1998. Climate extremes in Loess of China coupled with the strength of deep-water formation in the North Atlantic. Global and Planetary Change 18, 113-128.

Hays, J.D., Imbrie, J., Shackleton, N.J., 1976. Variations in the Earth's Orbit: Pacemaker of the Ice Ages. Science 194, 1121-1132.

Heller, F., Liu, T., 1984. Magnetism of Chinese loess deposits. Geophysical Journal of the Royal Astronomical Society 77, 125-141.

Kirkby, J., 2007. Cosmic rays and climate. Surveys in Geophysics 28, 333-375.

Kitaba, I., Hyodo, M., Katoh, S., Dettman, D.L., Sato, H., 2013. Midlatitude cooling caused by geomagnetic field minimum during polarity reversal. Proceedings of the National Academy of Sciences of the United States of America 110, 1215-1220.

Knudsen, M.F., Riisager, P., 2009. Is there a link between Earth's magnetic field and low-latitude precipitation? Geology 37, 71-74.

Kukla, G., 1987. Loess stratigraphy in central China. Quaternary Science Reviews 6, 191-219.

Laj, C., Channell, J., 2007. Geomagnetic excursions. Treatise on Geophysics 5, 373-416. Li, J., Fang, X., 1999. Uplift of the Tibetan Plateau and environmental changes. Chinese Science Bulletin 44, 2117-2124. 
Li, J., Fang, X., Van der Voo, R., Zhu, J., Niocaill, C.M., Ono, Y., Pan, B., Zhong, W., Wang, J., Sasaki, T., 1997. Magnetostratigraphic dating of river terraces: Rapid and intermittent incision by the Yellow River of the northeastern margin of the Tibetan Plateau during the Quaternary. Journal of Geophysical Research: Solid Earth (1978-2012) 102, 10121-10132. Lisiecki, L.E., Raymo, M.E., 2005. A Pliocene-Pleistocene stack of 57 globally distributed benthic $\delta^{18} \mathrm{O}$ records. Paleoceanography 20.

Liu, T., Ding, Z., 1998. Chinese loess and the paleomonsoon. Annual Review of Earth and Planetary Sciences 26, 111-145.

Lu, H.Y., Zhang, F.Q., Liu, X.D., 2003. Patterns and frequencies of the East Asian winter monsoon variations during the past million years revealed by wavelet and spectral analyses. Global and Planetary Change 35, 67-74.

Ning, S., Aldahan, A., Haiping, Y., Possnert, G., Königsson, L.-K., $1994 .{ }^{10}$ Be in continental sediments from North China: Probing into the last 5.4 Ma. Quaternary Science Reviews 13, 127-136.

Shi, Y., Yu, G., Liu, X., Li, B., Yao, T., 2001. Reconstruction of the 30-40kabp enhanced Indian monsoon climate based on geological records from the Tibetan Plateau. Palaeogeography, Palaeoclimatology, Palaeoecology 169, 69-83.

Steig, E., Polissar, P., Stuiver, M., Grootes, P., Finkel, R., 1996. Large amplitude solar modulation cycles of $10 \mathrm{Be}$ in Antarctica: implications for atmospheric mixing processes and interpretation of the ice core record. Geophysical Research Letters 23, 523-526.

Sun, J., Liu, T., 2000. Multiple origins and interpretations of the magnetic susceptibility signal in Chinese wind-blown sediments. Earth and Planetary Science Letters 180, 287-296.

Sun, J.M., 2000. Stratigraphic evidence for the uplift of the Tibetan Plateau between similar to 1.1 and similar to 0.9 myr ago. Quaternary Research 54, 309-320.

Sun, Y., An, Z., Clemens, S.C., Bloemendal, J., Vandenberghe, J., 2010. Seven million years of wind and precipitation variability on the Chinese Loess Plateau. Earth and Planetary Science Letters 297, 525-535.

Sun, Y.B., Clemens, S.C., An, Z.S., Yu, Z.W., 2006. Astronomical timescale and palaeoclimatic implication of stacked 3.6-Myr monsoon records from the Chinese Loess Plateau. Quaternary Science Reviews 25, 33-48. 
Tauxe, L., 1993. Sedimentary records of relative paleointensity of the geomagnetic field: theory and practice. Reviews of Geophysics 31,319-354.

Tilgner, A., 2006. Precession, Tides and the Geodynamo, AGU Spring Meeting Abstracts, p. 03.

Usoskin, I.G., Korte, M., Kovaltsov, G.A., 2008. Role of centennial geomagnetic changes in local atmospheric ionization. Geophysical Research Letters 35.

Valet, J.P., 2003. Time variations in geomagnetic intensity. Reviews of Geophysics 41.

Valet, J.P., Meynadier, L., Guyodo, Y., 2005. Geomagnetic dipole strength and reversal rate over the past two million years. Nature 435, 802-805.

Xiao, J.L., An, Z.S., 1999. Three large shifts in East Asian monsoon circulation indicated by loess-paleosol sequences in China and late Cenozoic deposits in Japan. Palaeogeography, Palaeoclimatology, Palaeoecology 154, 179-189.

Yeh, T., Lo, S., Chu, P., 1957. The wind structure and heat balance in the lower troposphere over Tibetan Plateau and its surrounding. Acta Meteorologica Sinica 28, 108-121.

Yin, Q., Guo, Z., 2008. Strong summer monsoon during the cool MIS-13. Climate of the Past 4, 29-34.

Zhou, L.P., Oldfield, F., Wintle, A.G., Robinson, S.G., Wang, J.T., 1990. Partly pedogenic origin of magnetic variations in Chinese loess. Nature 346, 737-739.

Ziegler, M., Lourens, L.J., Tuenter, E., Reichart, G.J., 2010. High Arabian Sea productivity conditions during MIS 13-odd monsoon event or intensified overturning circulation at the end of the Mid-Pleistocene transition? Climate of the Past 6, 63-76.

\section{Figure captions:}

Figure 1. Comparison of Chinese Loess Plateau paleoclimatic proxies with global records of $\delta^{18} \mathrm{O}$ and paleointensity. (a) magnetic susceptibility $\chi$ and Mean grain size (dashed, note reversed scale) of Lingtai loess. L1S, S5, L9 and L15 are the stages with climatic anomalies and are marked by vertical gray bars. (b) PISO-1500 compared with LR04 stacked $\delta^{18} \mathrm{O}$ (note reversed scale). Numbers indicate Marine Isotope Stage (MIS). (c) Sint-2000 compared with LR04 stacked $\delta^{18} \mathrm{O}$. The dots denote known geomagnetic excursions. LA-Laschamp, BLT-Big Lost, LP-La Palma, KA-Kamikatsura, SR-Santa 
Rosa, CB-Cobb Mt. Subchron, BJ-Bjorn. The vertical bars highlight the negative correlation between paleointensity (PISO-1500 and Sint-2000) and $\delta^{18} \mathrm{O}$.

Figure 2. Correlations between paleointensity and $\delta^{18} \mathrm{O}$. (a), (b), (c), (d) and (e) are the comparisons between PISO-1500 and LR04 stacked $\delta^{18} \mathrm{O}$ around MIS 3, 13, 22 and 38. (f), (g), (h), (i) and (j) are for Sint-2000 and $\delta^{18} \mathrm{O}$ around the four intervals.

Figure 3. Negative correlation between paleointensity and $\delta^{18} \mathrm{O}$ detected by cross correlation. (a) lags in cross correlation between relative paleointensity and $\delta^{18} \mathrm{O}$. (b) $\mathrm{X}_{\mathrm{CF}}$ in cross correlation between paleointensity and $\delta^{18} \mathrm{O}$. Circle is PISO-1500 vs. $\delta^{18} \mathrm{O}$, asterisk is for Sint-2000 vs. $\delta^{18} \mathrm{O}$. The bars highlight the intervals with high correlation between paleointensity and $\delta^{18} \mathrm{O}$. The intervals correspond to the climatic anomaly intervals.

Figure 4. Mechanism of climatic anomalies on the CLP. The combined actions of the climatic effects of the benthic $\delta^{18} \mathrm{O}$ and geomagnetic intensity produce the climatic anomalies on the CLP. 
Figure 1

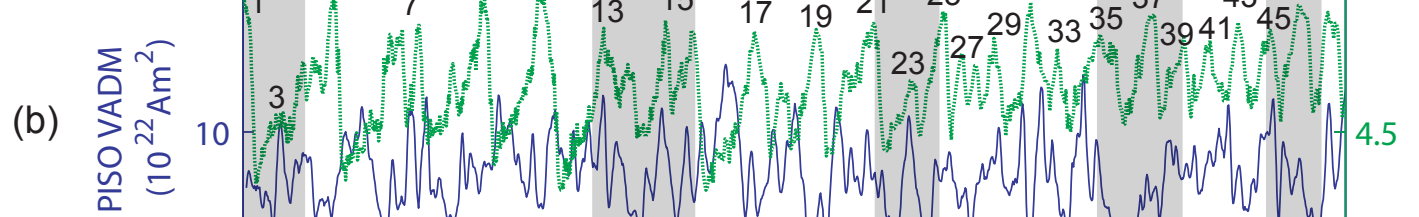

(c)

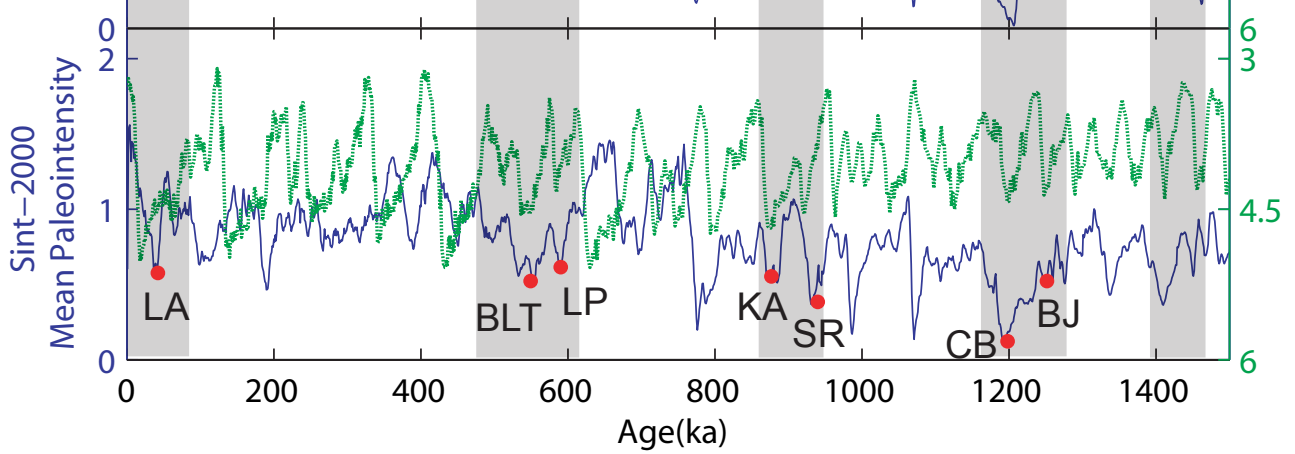

(1)

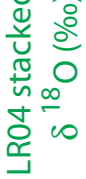

$\frac{\sqrt{0}}{\frac{0}{0}}$

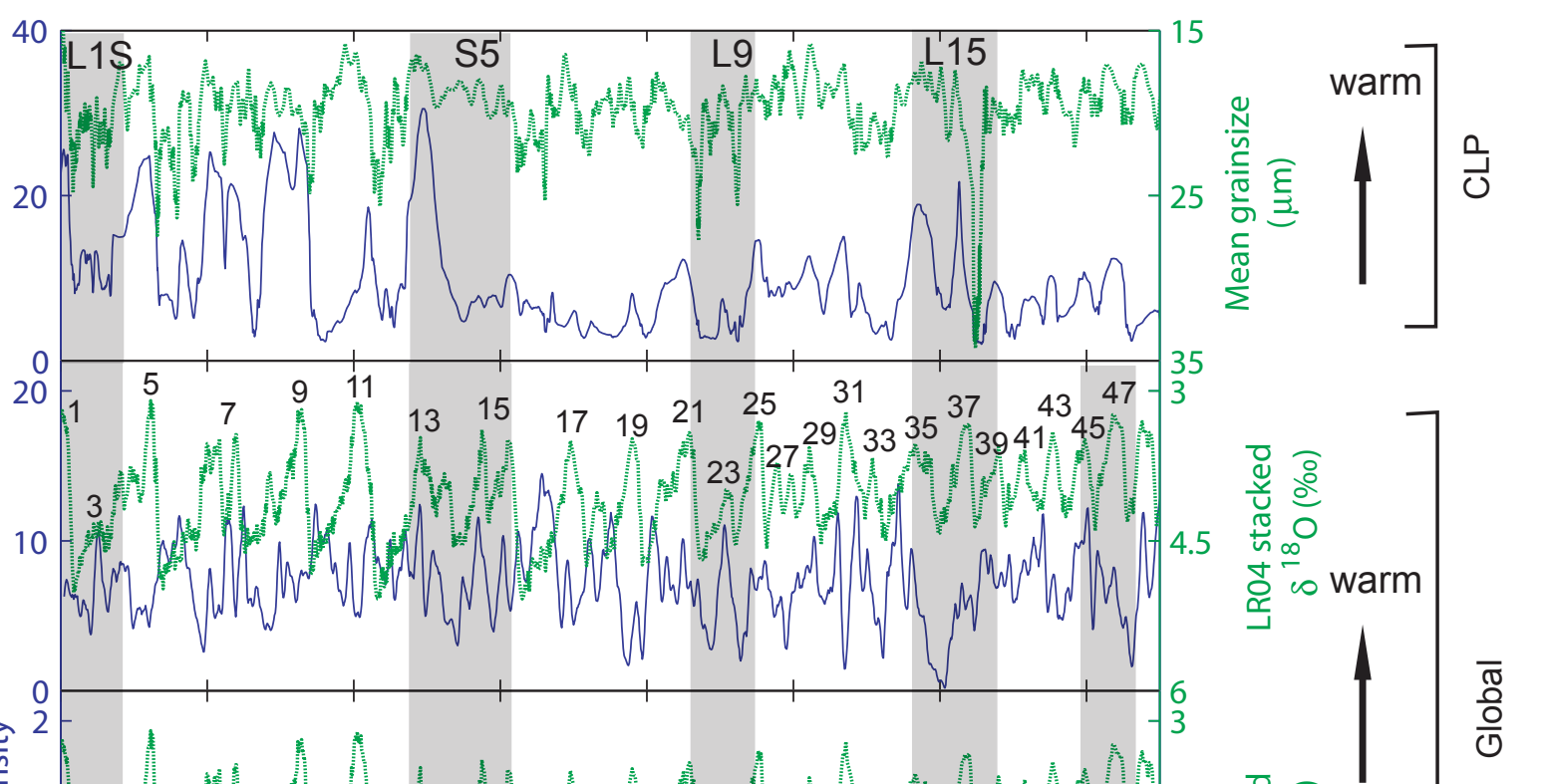

Age(ka) 

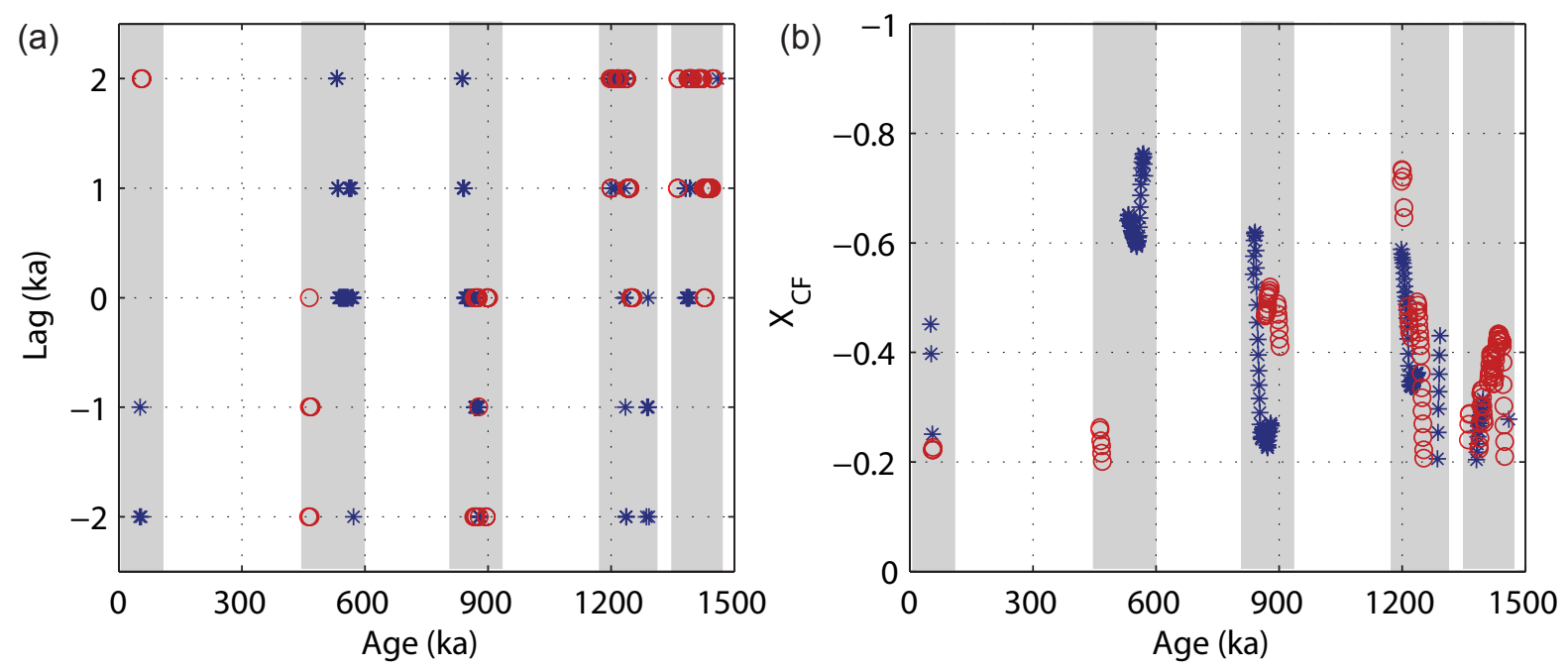


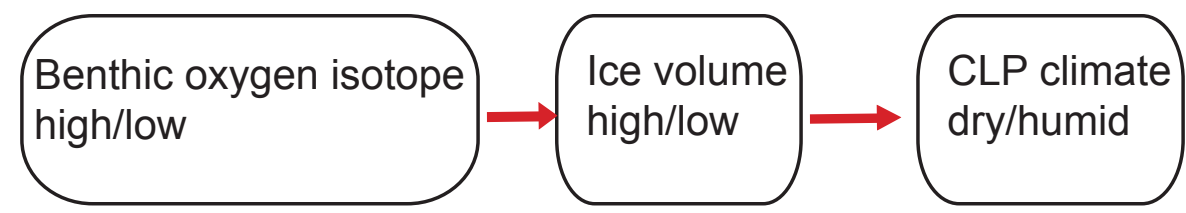

